\title{
ANALISIS POTENSI SUMBERDAYA MANGROVE DI DESA SARAWET, SULAWESI UTARA, SEBAGAI KAWASAN EKOWISATA
}

\section{(Analysis of Potential of Mangrove Resources in the Sarawet Village, North Sulawesi, for Ecotourism Developments)}

\author{
Peter Mangindaan $^{1^{*}}$, Adnan Wantasen ${ }^{2}$, Stephanus V. Mandagi ${ }^{2}$ \\ ${ }^{1}$ Program Pascasarjana, Universitas Sam Ratulangi, Manado, Sulawesi Utara. \\ ${ }^{2}$ Fakultas Perikanan dan Ilmu Kelautan Universitas Sam Ratulangi, Manado, Sulawesi Utara.
}

\begin{abstract}
Kawasan pesisir Desa Sarawet Likupang Timur memiliki mangrove seluas 379 hektar dan memiliki potensi untuk dikembangkan sebagai kawasan ekowisata. Berdasarkan hal tersebut, penelitian ini bertujuan untuk (1) Menganalisis struktur komunitas hutan mangrove di Desa Sarawet (2) Mengkaji potensi kawasan pesisir Desa Sarawet untuk dikembangkan menjadi kawasan ekowisata berbasismangrove. Hasil analisis terhadap 6 variabel yaitu sumberdaya alam, budaya lokal, sosial-ekonomi masyarakat, infrastuktur kawasan, institusional dan kemungkinan dampak di kawasan pesisir Desa Sarawet menghasilkan nilai 3,7. Nilai ini menunjukkan bahwa kawasan pesisir Desa Sarawet berada pada level moderat yang berarti dapat dikembangkan sebagai kawasan ekowisata berbasis mangrove,
\end{abstract}

Kata kunci: Sarawet; ekowisata; mangrove

Coastal village of East Likupang Sarawet has 379 hectares of mangrove area and has the potential to be developed as an ecotourism area. Accordingly, this study aimed to (1) To analyze the community structure of mangrove forest in the village of Sarawet (2) To assess the potential of the coastal village of Sarawet to be developed into a mangrove-based ecotourismregion. The results of the analysis on six variables, namely natural resources, local culture, socio-economic communities, regional infrastructure, institutional and likely impact on the coastal village of Sarawet produce a value of 3.7. This value indicates that the coastal village of Sarawet is at the moderate level wich means it can be developed as a mangrove-based ecotourism area.

Keywords: Sarawet; ecotourism; mangroves

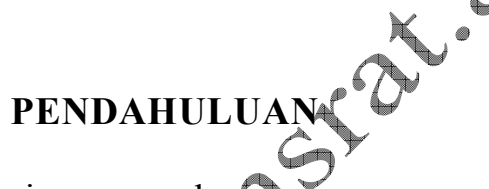

Indonesia merupakan hegara yang memiliki potensi mangrove terluas di dunia. Luas total hutan mangrove di cunia 18 juta hektar, dan seperempatnya 5,5 juta hektar, dimiliki Indonesia (BPHM, 2000). Kondisi hutan mangrove di Indonesia semakin banyak mendapat tekanan baik fisik maupun ekologis, diantaranya karena masib rendahnya kesadaran masyarakat untuk nenjaga kelestarian hutan mangrove dan meningkatnya kebutuhan ekonomi sebagai pemicuterhadap penurunan luas dan kualitas lingkungan hutan mangrove. Luasan hutan mangrove di Indonesia turun dari 5,21 juta hektar antara tahun 1982-1987 menjadi 3,24 juta hektar dan makin menyusut menjadi 2,5 juta hektar pada tahun 1993 (Widigdo, 2000).

Salah satu sektor unggulan pembangunan di Sulawesi Utara adalah pariwisata. Salah satu strategi yang ditempuh pemerintah untuk mengembangkan sektor pariwisata adalah dengan mencari, membangun, dan mengembangkan ODTW (Objek dan Daya Tarik Wisata) baru. Setiap tempat, lokasi atau kawasan yang dianggap berpotensi, akan dikembangkan menjadi ODTW, sehingga diharapkan semakin banyak wisatawan yang berkunjung ke daerah tersebut. Provinsi Sulawesi Utara memiliki beberapa lokasi dan kawasan yang menyimpan potensi wisata tapi belum dikembangkan, termasuk termasuk di dalamnya adalah kawasan pesisir. Desa Sarawet Kecamatan Likupang Timur Kabupaten Minahasa Utara memiliki potensi untuk dapat dikembangkan sebagai kawasan ekowisata karena memiliki hutan mangrove dengan luasan 379 hektar.

Berdasarkan potensi tersebut penelitian ini dilakukan dengan tujuan untuk menganalisis struktur komunitas hutan mangrove dan mengkaji potensi kawasan pesisir Desa Sarawet untuk dikembangkan menjadi kawasan ekowisata berbasis mangrove. 


\section{METODE PENELITIAN}

\section{Lokasi Penelitian}

Penelitian dilakukan di kawasan pesisir Desa Sarawet Kecamatan Likupang Timur Kabupaten Minahasa Utara selama 6 (enam) bulan pada tiga dusun yakni Dusun Sarawet, Dusun Kuala Batu dan Dusun Rasaan.

\section{Metode Penelitian}

Data yang dikumpulkan dalam penelitian ini berupa data primer dan sekunder. Data primer dikumpulkan melalui pengamatan langsung di lapangan dan wawancara dengan $40 \mathrm{ru}-$ mah tangga responden yang dipilih secara acak dengan menggunakan daftar pertanyaan yang telah disediakan. Data sekunder dikumpulkan dari berbagai kajian literatur, data desa, dokumentasi, tulisan-tulisan ilmiah dan data dari BPDAS Tondano. Objek penelitian adalah kawasan mangrove yang dinilai memiliki potensi sebagai kawasan ekowisata di kawasan pesisir Desa Sarawet.

\section{Metode Pengumpulan Data}

Pengumpulan data kondisi mangrove menggunakan transek kuadran berukuran $25 \times 25$ meter yang diletakkan tegak lurus garis pantai sebanyak 3 buah setiap lokasi dengan 2 ulangan di 3 lokasi berbeda yaitu Dusun Sarawet, Dusun Kuala Batu dan Dusun Rasaan. Pada sétiap kuadrat dilakukan penghitungan jumlahjonis individu, diameter batang dan pengamatan kondisi substrat. Pengumpulan data primer melalui kuisioner diperoleh dari 40 responden yang dipilih secara acak. Informasi yang diperoleh dari kuisioner terdiri atas 6aspek yakni aspek sumberdaya alam, sosial ekonømi, budaya lokal, institusional, infrastraktur dan kemungkinan dampak. Untuk data sekunder diperoleh dari berbagai literatur dar data desa, dokumentasi, tulisan ilmiah, data BPDAS Tondano dan lainnya yang telah tersedia.

\section{Metode Analisis Data}

Analisis data kondisi ekologi dilakukan melalui perhitungan indeks keragaman (Ludwig dan Reynolds, 1988):

Keragaman (Diversity) Shannon-Wienner:

$$
\mathrm{H}^{\prime}=-\sum_{\mathrm{i}=1}^{\mathrm{s}}\left(\frac{\mathrm{n}_{\mathrm{i}}}{\mathrm{N}}\right) \log \left(\frac{\mathrm{n}_{\mathrm{i}}}{\mathrm{N}}\right)
$$

dimana:

$\mathrm{H}^{\prime}=$ indeks keragaman

$\mathrm{n}_{\mathrm{i}}=$ nilai tiap individu dalam petak ukur

$\mathrm{N}=$ total jumlah individu

$\mathrm{s} \quad=$ jumlah genera

Selain evaluasi struktur komunitas, juga dilakukan perhitungan nilai kepadatan, kepadatan relatif, dominansi, dominansi relatif, frekuensi, dan frukensi relatif dan nilai penting dengan mengikuti cara seperti yang dikemukakan Snedaker dan Snedaker (1984):

- Kepadatan

- Kepadatan relatif

$$
\mathrm{K}=\frac{\text { Jumlah individu }}{\text { Luas areal }}
$$

$$
\mathrm{K}_{\mathrm{r}}=\frac{\text { Total individu setjap spesies }}{\text { Total individu seluruh spesies }} \times 100
$$

- Basal area

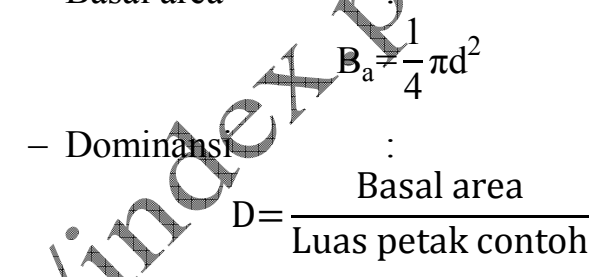

Dominansi relatif :

$$
\mathrm{D}_{\mathrm{r}}=\frac{\text { Dominansi suatu jenis }}{\text { Dominansi seluruh jenis }} \times 100
$$

- Frekuensi

$\mathrm{F}=\frac{\text { Jumlah petak ukur yang berisi suatu jenis }}{\text { Jumlah seluruh petak ukur }}$

- Frekuensi relatif :

$$
\mathrm{F}_{\mathrm{r}}=\frac{\text { frekuensi suatu jenis }}{\text { frekuensi seluruh jenis }} \times 100
$$

- Indeks nilai penting :

$$
\mathrm{N}_{\mathrm{P}}=\mathrm{K}_{\mathrm{r}}+\mathrm{D}_{\mathrm{r}}+\mathrm{F}_{\mathrm{r}}
$$

Analisis data potensi ekowisata dianalisis secara deskriptif dan dilakukan analisis ekologi, dengan menentukan tingkat kelayakan pengembangan kawasan. Untuk mencapai tujuan ini data potensi dianalisis dengan metode scoring. Setiap parameter dari enam aspek potensi yaitu sumberdaya alam, sosial ekonomi, budaya lokal, institusional, infrastruktur, dan kemungkinan dampak, diberi bobot penilaian berdasarkan kategori yang telah ditetapkan. Pembobotan ini terdiri 5 level, level 1 bermakna poor atau miskin, level 2 bermakna moderate to poor atau mendekati miskin, level 3 bermakna moderate, level 4 bermakna moderate to good atau mendekati baik dan level 5 bermakna good atau baik. 
Untuk level 1 dan 2 berada pada kondisi yang tidak memungkinkan untuk dikembangkan. Level 3 berarti potensi berada pada kondisi seadanya, level 4 dan 5 dikategorikan tinggi yang berarti memungkinkan potensi untuk dikembangkan (Priskin, 2001).

Evaluasi bentuk pengelolaan yang tepat guna pengembangan pesisir Desa Sarawet sebagai kawasan ekowisata berbasis mangrove dilakukan dengan 2 pendekatan yakni Government Centralized Management (GCM), dan Community Based Management (CBM). GCM mengeluarkan aturan, pengambilan keputusan, strategi pengelolaan sumberdaya di daerah tanpa melibatkan masyarakat. Sedangkan CBM meletakkan pengetahuan dan kesadaran lingkungan masyarakat lokal sebagai dasar pengelolaan yang tradisional, dengan melihat budaya dan kepercayaan tersendiri sehingga masyarakat diberikan kesempatan dan tanggung jawab dalam melakukan pengelolaan terhadap sumberdaya yang dimilikinya, sehingga masyarakat sendiri yang mendefinisikan kebutuhan, tujuan dan aspirasinya serta membuat keputusan demi kesejahteraannya. Pengelolaan yang mampu menampung kepentingan masyarakat maupun kepentingan lainnya adalah konsep Cooperative Management atau disingkat dengan Co-Management. Dalam konsep ini, masyarakat lokal merupakan partner penting bersama-sama dengan pemerintah dan pihak terkait lainnya dalam pengelolaan sumberdaya alam di suatu kawân.

\section{HASIL DAN PEMBAHASAN}

\section{Komposisi dan Distribusi Mangrove}

Dari ketiga stasiun diperoleh 1220 individu dari 5 spesies mangroye, selengkapnya pada Tabel 1. Berdasarkan perhitungan secara kuantitatif, ditemukankomunitas mangrove di kawasan pesisir Desa Sarawet bervariasi pada ke 3 stasiun.

\section{Keragaman:}

Nilai keragaman tertinggi didapati di stakin $y$ dengan jumlah $\mathrm{H}^{\prime}=0,27$ diikuti stasiun $2(0,29)$ dan stasiun $3(0,30)$. Hal ini menunjukkan bahwa di stasiun 1, 2 dan 3 memiliki keanekaragaman yang rendah karena memiliki nilai keragaman di bawah 2 (Tabel 2). Keanekaragaman jenis digunakan untuk mengukur kemampuan suatu komunitas dalam menjaga dirinya terhadap gangguan dan dapat digunakan untuk mengukur kekayaan komunitas dilihat dari jumlah spesies dalam suatu kawasan, semakin ba- nyak jumlah spesis maka semakin tinggi keanekaragaman (Soegianto, 1994).

Tabel 1. Family, spesies, nama lokal dan jumlah individu menurut lokasi penelitian.

\begin{tabular}{|c|c|c|c|c|c|}
\hline \multirow{2}{*}{ Famili } & \multirow{2}{*}{ Spesies } & \multirow{2}{*}{$\begin{array}{l}\text { Nama } \\
\text { Lokal }\end{array}$} & \multicolumn{3}{|c|}{ Stasiun } \\
\hline & & & 1 & 2 & 3 \\
\hline Avicenniaceae & $\begin{array}{l}\text { Avicenia } \\
\text { alba }\end{array}$ & Api-api & . & 25 & - \\
\hline Rhizophoraceae & $\begin{array}{l}\text { Bruguiera } \\
\text { gymnorizha }\end{array}$ & $\begin{array}{l}\text { Mangi- } \\
\text { mangi }\end{array}$ & 144 & 80 & 30 \\
\hline Rhizophoraceae & $\begin{array}{l}\text { Rhizophora } \\
\text { apiculata }\end{array}$ & $\begin{array}{l}\text { Lolaro } \\
\text { merah }\end{array}$ & - & & 200 \\
\hline Lythraceae & $\begin{array}{l}\text { Sonneratia } \\
\text { alba }\end{array}$ & Posi-posi & & & \\
\hline Arecaceae & $\begin{array}{l}\text { Nypa } \\
\text { fruticans } \\
\end{array}$ & Nipah & & & 4 \\
\hline & & TOTAL & 522 & 445 & 253 \\
\hline
\end{tabular}

Tabel 2. Indeks keragaman mangrove di lokasi penelitian.

\begin{tabular}{|c|c|c|c|c|c|}
\hline Spesies & $\sum \mathrm{Sp}$ & & $n i f$ & $\log \mathbf{p i}$ & pi $\log$ pi \\
\hline \multicolumn{6}{|l|}{ Stasiun 1} \\
\hline B.gymnorizha & 144 & & 0.28 & -0.56 & -0.15 \\
\hline S.alba & 375 & & 0.72 & -0.14 & -0.10 \\
\hline N.fruticans & 3 & 522 & 0.01 & -2.24 & -0.01 \\
\hline & $y$ & & & H' & 0.27 \\
\hline \multicolumn{6}{|l|}{ Stasiun 2} \\
\hline A.alba & 25 & 445 & 0.06 & -1.25 & -0.07 \\
\hline B.gymnerizha & 80 & 445 & 0.18 & -0.75 & -0.13 \\
\hline R.apiculator & 340 & 445 & 0.76 & -0.12 & -0.09 \\
\hline$A \mid Y$ & & & & $\mathrm{H}^{\prime}$ & 0.29 \\
\hline \multicolumn{6}{|l|}{ Stasiun 3} \\
\hline B.gymnorizha & 30 & 253 & 0.12 & -0.93 & -0.11 \\
\hline R.apiculata & 200 & 253 & 0.79 & -0.10 & -0.08 \\
\hline S.alba & 19 & 253 & 0.08 & -1.12 & -0.08 \\
\hline \multirow[t]{2}{*}{ N.fruticans } & 4 & 253 & 0.02 & -1.80 & -0.03 \\
\hline & & & & H' & 0.30 \\
\hline
\end{tabular}

\section{Kepadatan:}

Nilai kepadatan tertinggi didapati pada stasiun 1 kuadran 1 yakni pada Bruguiera $(0,20)$ dan nilai relatif $96,26 \%$. Untuk kuadran 2 nilai tertinggi ada pada Sonneratia $(0,59)$ dengan nilai relatif $95,3 \%$. Nilai tertinggi pada stasiun 2 kuadran 1 berada pada Rhizophora $(0,2)$ dan nilai relatifnya $58,13 \%$ untuk nilai terendah berada pada Avicenia $(0,04)$, nilai relatif $11,62 \%$. Pada kuadran 2 nilai tertinggi pada Rhizophora $(0,34)$ dengan nilai relatif $93,47 \%$, nilai terendah pada Bruguiera 0,02 dan nilai relatif 6,52\%. Untuk stasiun 3 kuadran 1 nilai tertinggi pada Rhizophora $(0,28)$, dan terendah pada Sonneratia $(0,01)$. Kepadatan relatif Rhizophora $86,63 \%$, Sonneratia 3,46\%. Dan untuk kuadran 2 nilai tertinggi pada Rhizophora $(0,04)$, nilai relatif $49,01 \%$ terendah Nypa $(0,006)$, nilai relatif $7,84 \%$ (Gambar 1). Nilai kepadatan suatu jenis menunjukkan kelimpahan spesies dalam suatu ekosistem dan nilai ini dapat menggambarkan bahwa jenis dengan kepadatan tertinggi memiliki pola penyesuaian 
yang besar. Kepadatan sangat dipengaruhi oleh jumlah spesies di daerah penelitian.

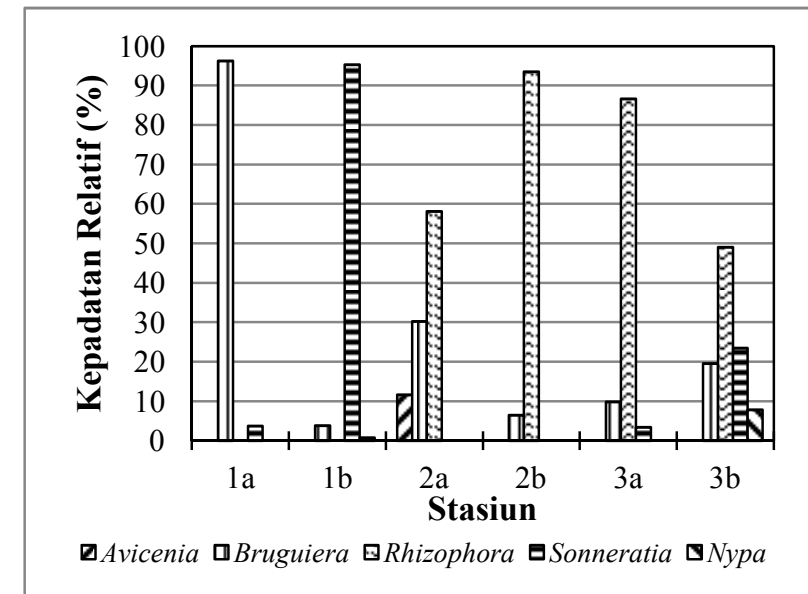

Gambar 1.Kepadatan relatif pada tiap stasiun penelitian.

\section{Basal Area:}

Nilai basal area tertinggi adalah spesies Bruguiera $\left(314 \mathrm{~cm}^{2}\right)$ yang terdapat pada stasiun 1 kuadran 1 sedangkan nilai yang terendah adalah Sonneratia, di kuadran 2 nilai basal tertinggi pada Sonneratia $\left(113,04 \mathrm{~cm}^{2}\right)$. Untuk stasiun 2 kuadran 1 nilai basal tertinggi berada pada spesies Bruguiera $\left(1962,50 \mathrm{~cm}^{2}\right)$, dan terendah pa= da Nypa $\left(78,50 \mathrm{~cm}^{2}\right)$, untuk kuadran 2 nilai tertinggi pada Bruguiera $\left(961,62 \mathrm{~cm}^{2}\right)$ dan pada stasiun 3 kuadran 1 nilai basal tertinggi pada Sonneratia $\left(706,50 \mathrm{~cm}^{2}\right)$ dan yang terendah pada Bruguiera $\left(28,26 \mathrm{~cm}^{2}\right)$. Kuadran 2 nilai 1256 $\mathrm{cm}^{2}$ pada spesies Nypa dan terendah pada Bruguiera (Gambar 2). Basal area meyupakan luas proyeksi dari tumbuhan padarpermukaan tanah. Di mana nilai dipengaruhiele, diameter batang pohon, semakin besar điameter batang pohon maka semakin besar pulanilai basal area.

\section{Dominansi:}

Brugutera untuk stasiun 1 kuadran 1 memiliki nilai dominasi 0,56 dengan nilai relatif 38,73\%, nilai, terendăh pada kuadran ini didapati pada Sonnexatla dengan nilai 0,36 dan nilai relatif $28,00 \%$ Kuadran 2 Sonneratia $(0,18)$ dengan nilai relatif $13,88 \%$ dan nilai terendah pada Bruguiera dan Nypa sebesar 9,64\% (Gambar 3). Stasiun 2 nilai tertinggi untuk kuadran 1 berada pada $\mathrm{Bru}$ guiera 3,14 dengan nilai relatif $50,49 \%$ dan terendah pada Rhizophora $(0,28)$ nilai realtif $4,55 \%$, kuadran 2 Bruguiera memiliki nilai tertinggi 1,53 (nilai relatif 24,75\%) nilai terendah pada Rhizophora $(0,12)$ nilai relatif $2,02 \%$. Sonneratia memiliki nilai tertinggi $(1,13)$ pada stasiun 3 kuadran 1, do- minansi relatif $24,06 \%$ dan terendah Bruguiera 0,04 dominansi relatif $0,95 \%$. Untuk kuadran 2 nilai terendah pada Bruguiera $(0,01)$ dominansi relatifnya $0,25 \%$ dan nilai tertinggi pada $N y p a$ $(2,01)$ dominansi relatif $42,80 \%$. Nilai dominasi menyatakan suatu jenis tumbuhan utama yang mempengaruhi dan melaksanakan kontrol terhadap komunitas dengan cara memperbanyak jumlah jenis, besarnya ukuran maupun pertumbuhan yang dominan, Odum (1971).

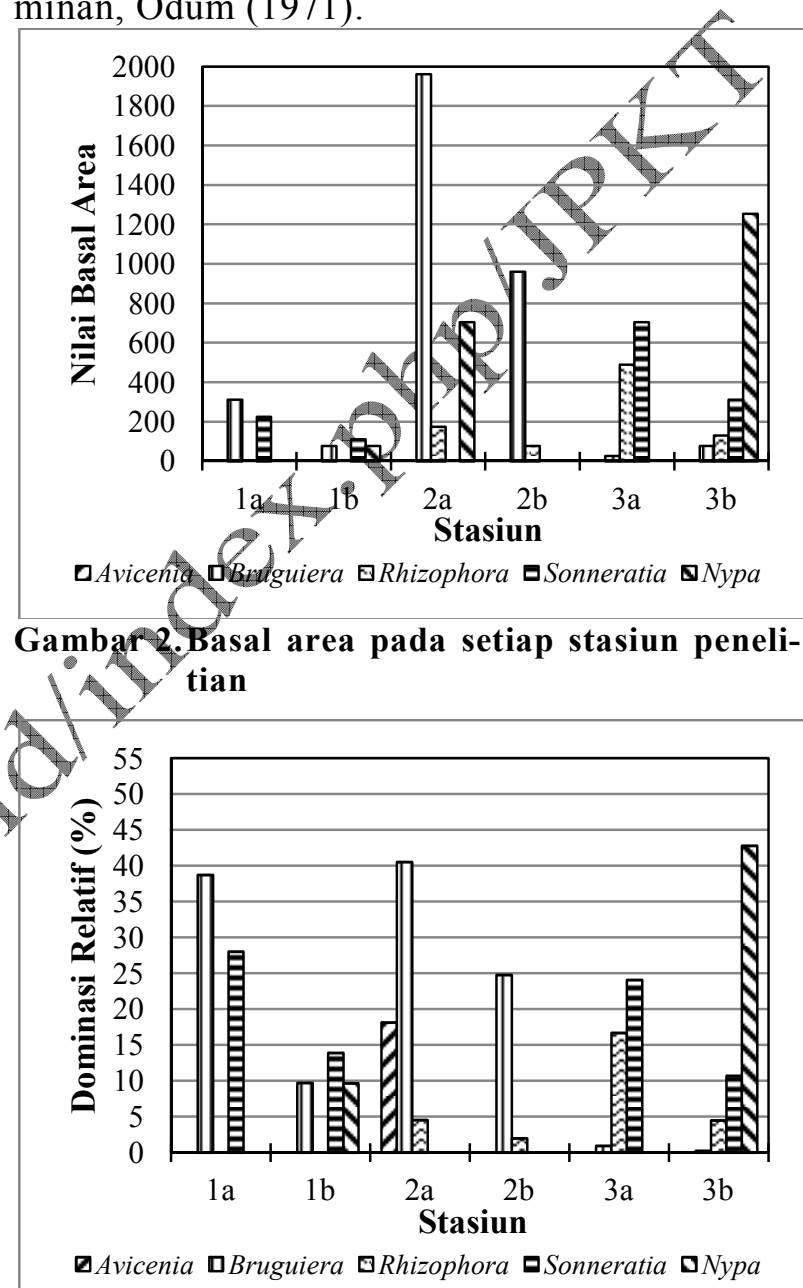

Gambar 3.Dominansi relatif pada tiap stasiun penelitian.

\section{Frekuensi:}

Spesies Bruguiera memiliki frekuensi senilai 1 dan nilai relatifnya $16,66 \%$, Sonneratia memiliki frekuensi terendah pada stasiun 1 kuadran 1 dengan nilai 0,66 dan nilai relatif $11,1 \%$. Untuk kuadran 2 nilai tertinggi masih berada pada Bruguiera, frekuensi dan nilai relatif sama dengan pada kuadran 1, Nypa yang memiliki nilai terendah 0,33 dan nilai relatifnya $5,55 \%$. Pada stasiun 2 nilai tertinggi berada pada Bruguiera dengan nilai 1 dan nilai relatif $16,66 \%$, nilai terendah pada Avicenia 0,16 dan nilai relatif 2,76\% pada kuadran 1, untuk kuadran 2 nilai tertinggi sa- 
ma dengan kuadran sebelumnya spesies Bruguiera memiliki nilai tertinggi dan nilai terendah pada Rhizophora 0,66 dan nilai relatinya $11,1 \%$, (Gambar 4). Menurut Fachrul (2007), frekuensi merupakan salah satu parameter vegetasi yang dapat menunjukan pola distribusi atau sebaran jenis tumbuhan dalam ekosistem atau pola distribusi tumbuhan. Nilai frekuensi dipengaruhi oleh nilai petak spesies mangrove yang ditemukan.

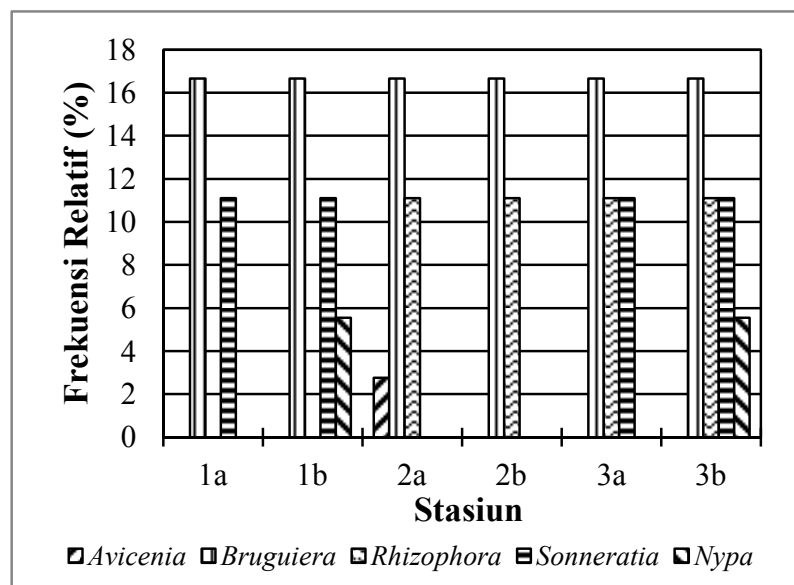

Gambar 4.Frekuensi relatif pada tiap stasiun penelitian.

\section{Indeks Nilai Penting (INP):}

INP tertinggi ditemukan pada spesies $B r{ }^{\circ}$ guiera $151,66 \%$ dan yang terendah berada pada spesies Nypa dengan nilai 15,96\% (Gambar $\$$ ) Menurut Mueller dan Ellenberg (1974), besar INP berkisar 0-300\%, di mana semakin besar INP berarti spesies yang bersangkutan berperan semakin besar dalam komunitas tersebut. Sudah_sangat jelas hasil dari analisis Bruguiera merupakan mangrove yang memiliki pengaruh besarterhadap jenis mangrove yang lain di kawasan pesisir Sarawet. Hal ini menggambarkan konđisi lingkungan perairan yang stabil.

\section{Inventarisasi Potensi Ekowisata di Kawasan Pesisir Desa Saráwet}

\section{Sumberdaya Alam:}

- Sumberdaya alam di kawasan pesisir Desa Sarawet sangat potensial bila untuk pengembangan kawasan ekowisata. Menurut Damanik dan Weber (2006) menyatakan potensi pengembangan wisata dapat ditilik melalui pendekatan bentang alam, di mana semakin lengkap rona bentang alam dalam suatu kawasan, maka semakin berpotensi kawasan tersebut untuk dikembangkan sebagai kawasan ekowisata. Untuk bentang alam di kawasan Sarawet beragam dan hampir lengkap karena terdapat laut, pantai, pulau kecil, pegunungan, hutan mangrove dan sungai. Dengan demikian sumberdaya alam di kawasan pesisir Sarawet sangat potensial untuk dikembangkan menjadi kawasan ekowisata. Di antara Pulau Napomanuk, Dusun Rasaan dan Dusun Kuala Batu, sering terlihat dugong berenang menyusur pinggiran pantai pada waktu-waktu tertentu, bahkan seringkali terperangkap dalam sero. Munculnya dugong di kawasan ini karena terdapat ekosistem padang lamun yang sangat luas sebagai tempat mencari makan.

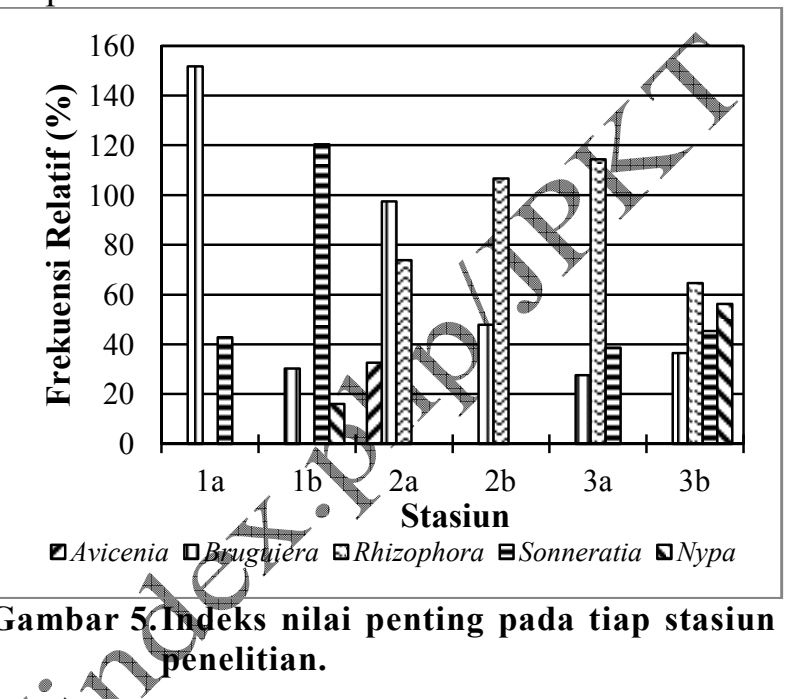

\section{Sosial Ekonomi:}

Sosial ekonomi masyarakat lokal kawasan pesísir Desa Sarawet dideskripsikan melalui tiga aspek yakni pendidikan, jenis pekerjaan dan kebiasaan hidup sehari-hari. Jumlah penduduk Desa sebanyak 1079 jiwa atau 326 kepala keluarga. Tingkat pendidikan penduduk adalah SD $(59,2 \%)$, SMP (20,4\%), SMA (15\%), tidak bersekolah $(31,7 \%)$ dan masyarakat yang mengenyam Perguruan Tinggi $(5,3 \%)$. Jenis pekerjaan penduduk sebagian besar sebagai petani $(58,8 \%)$, dan nelayan $(3,6 \%)$, sisanya sebagai PNS dan TNI/POLRI, pedagang, jasa dan pekerja swasta. Beberapa dari masyarakat memiliki pekerjaan ganda, hal ini berkaitan dengan kondisi dan situasi lingkungan. Jika cuaca buruk dan keadaan laut yang tidak memungkinkan, nelayan merubah mata pencahariannya menjadi petani.

\section{Budaya Lokal:}

Inventarisasi budaya lokal teridentifikasi sebanyak 3 komponen, yaitu atraksi budaya, kearifan lokal dan produk kerajinan. Budaya lokal ini bersama dengan potensi sumberdaya alam merupakan aspek penting dalam pengembangan ekowisata. Atraksi budaya, kearifan lokal dan produk kerajinan ini bisa dikembangkan menjadi produk dan aset utama pada industri ekowisata secara bersama dengan komponen sumberdaya alam, (Damanik dan Weber, 2006). Budaya lokal di kawasan pesisir Desa Sarawet dapat dilihat pada Tabel 3. 
Tabel 3. Keragaman Budaya Lokal di Kawasan Sarawet

\begin{tabular}{cc}
\hline Bentuk Nama & Penjelasan \\
\hline
\end{tabular}

\begin{tabular}{|c|c|}
\hline 1. Atraksi Budaya & \\
\hline a. Tarian Masamper & $\begin{array}{l}\text { Tarian khas etnis Sangihe yang } \\
\text { berkaitan dengan upacara adat }\end{array}$ \\
\hline
\end{tabular}
berkaitan dengan upacara adat ungkapan syukur kepada Pencipta.

b. Tradisi Tulude Upacara adat etnis Sangihe untuk menyatakan syukur atas penyertaan Tuhan selama setahun yang telah lewat dan memohon pertolongan Tuhan untuk tahun yang akan datang.

Pengucapan Tradisi mengucap syukur kepaSyukur da Tuhan atas hasil panen dan kerja dalam setahun. Masyarakat beribadah dan membawa hasil panen ke gereja, sesudah itu menggelar acara makan-minum bersama kerabat dan kenalan. Biasanya digelar pada bulan Juni-Juli, dan jalan di kawasan ini menjadi sangat macet karena dipenuhi orang-orang yang hendak berkunjung ke kerabat atau kenalannya.

Badana Tarian dengan mengetuk gambus sambil berpantun, yang terdiri 6 sampai 7 orang.

2. Kearifan Lokal

Goso

Blanga

Pelarangan membersihkan alate alat dapur di pantai. Jika ketahuan akan dikenakan sanksiua- 。 dat dan harus dilakukan proses penghapusan, agar tidak terjadi ombak besar yang dapat merusak pemukiman penduduk.

\section{Produk Kerajinan}

Anyaman daun Nypa

Daun Nypa di anyam menjadi tas, tikar, dand dijadikan atap rumah pengganti seng aluminium

\section{Institusional:}

Aspek kelembagaan menyangkut keberadaan dari organisasi-organisasi yang berinteraksi dalam kawasan untuk kepentingan pengembangan ekowisata. Organisasi bisa saja dalam bentuk formal dan informal yang berada pada tingkat lokal bahkan kewilayahan. Untuk Desa Sarawet belum ditemukan adanya kelembagaan yang formal atau informal dalam pengelolaan kawasan wisata, objek wisata, pencinta objek wisata dan kelompok pengrajin, hanya ditemukan satu usaha perorangan dalam pembibitan mangrove dan mengawasi mangrove di kawasan ini yang melibatkan masyarakat menjadi pelaku utama dalam usaha pembibitan. Menyangkut regulasi, di Desa Sarawet belum ada regulasi di tingkat lokal (seperti Peraturan Desa atau yang lain) berkaitan dengan pariwisata, hanya ditemukan larangan bagi masyarakat untuk mene- bang pohon mangrove dengan maksud untuk menjaga kelestarian hutan mangrove dan sumber nutrien biota lainnya, dimana aturan ini sudah sangat dipahami oleh masyarakat lokal.

\section{Infrastruktur:}

Menurut Damanik dan Weber (2006), kawasan memiliki dua aspek infrastruktur yaitu infrastruktur fisik dan non fisik, dimana infrastruktur fisik terdiri dari aksesibitas, fasilitas, penataan kawasan dan keberadaan objek wisata, sedangkan non fisik meliputi keamanan dan kenyamanan, juga persepsi masyarakat tentang ekowisata. Aspekaspek tersebut menjadi informasi sebagai perumusan strategi pengembangan ekowisata.

Kondisi jalan untuk mencapai kawasan ini sangat baik, dari Manado dapat ditempuh dalam waktu 60 menit dengan tarif Rp. 15.000, sedangkan dari Likupang Kabupaten Minahasa Utara hanya membutuhkan waktu 10 menit. Selain jalan darat, perjalanan dári Manado dapat juga ditempuh melalui perjalanan laut. Transportasi utama masyarakat di kaurasan ini adalah sepeda motor, ada juga kendaraan pribadi yang dijadikan sebagai angkutan umam dar kawasan pesisir Sarawet menuju Manado ataษ ke daerah-daerah di Kabupaten Minahasa Dtara.

Semua masyarakat menggunakan fasilitas listrik dari Perusahan Listrik Negara (PLN), namun untuk penerangan jalan hanya perkampungan penduduk saja yang diberikan penerangan tanpa adanya lampu jalan. Sebagian besar masyarakat menggunakan fasilitas telepon seluler dengan jaringan yang relatif baik, dan belum ada jaringan telepon kabel dari PT. Telkom yang masuk ke kawasan ini.

Untuk air bersih, masyarakat menggunakan sumur dan juga bak penampungan mata air pegunungan yang disambungkan ke bak-bak perumahan dengan menggunakan pipa sebagai kebutuhan sehari-hari, karena belum adanya jaringan pipa-pipa air bersih dari pemerintah.

Berhubung belum adanya lokasi objek wisata di kawasan Pesisir Sarawet, biasanya masyarakat setempat melakukan perjalanan wisata di pantai Surawaya Likupang Dua atau menuju ke Pulau Lihaga yang bersebelahan dengan Pulau Gangga. Sebagai alternatif tempat wisata yang mulai dikunjungi masyarakat setempat adalah Pulau Napomanuk atau sering dikatakan sebagai Pulau Mangrove. Untuk melakukan wisata ke pulau tersebut sangat tergantung pada kondisi pasang-surut perairan, dimana harus menunggu surut baru bisa melakukan kegiatan wisata, begitu juga sebaliknya saat air pasang masyarakat harus bergegas meninggalkan pulau terse- 
but. Kondisi tersebut menyebabkan sebagian masyarakat enggan berkunjung ke tempat tersebut. Dari 40 responden yang dimintai pendapat $82 \%$ pernah mendengar ekowisata tapi tidak mengerti apa itu sebenarnya ekowisata, $18 \%$ responden mengakui belum pernah mendengar tentang ekowisata. Dari $82 \%$ responden, sebanyak 10 responden yang mengerti ekowisata sebagai bentuk pariwisata berbasis mangrove dengan peran aktif dari masyarakat.

\section{Kemungkinan Dampak:}

Semakin kecil dampak negatif yang terjadi, semakin besar potensi pengembangan ekowisata pada suatu kawasan. Maksud dan tujuan dari ekowisata yang mengedepankan konservasi alam dan lingkungan hidup sangat layak untuk dikembangkan di kawasan pesisir Desa Sarawet. Konsep ekowisata juga sangat menghargai kehidupan lokal berupa budaya, sosial dan ekonomi, dimana masyarakat lokal sangat berperan dalam pengembangan ekowisata dalam hal penggunaan fasilitas yang dikelola masyarakat serta wisatawan yang berkunjung dapat belajar kehidupan masyarakat lokal. Apabila konsep ekowisata diterapkan dengan baik pada kawasan pesisir Desa Sarawet, dampak yang diharapkan akan terjadi yakni kontribusi positif bagi kelestarian ekosistem. Pertunjukan lokal yang merupakan bagian kehidupan budaya setempat dapat dijadikan kegiatan untuk menarik wisatawan, walaupun demikian penting sekali penekanan dalam ekowisata bahwa wisatawan tidak mempengaruhi budaya dan kehidupan lokal, agar supaya ekowisata bisa menjadi sarana edukas baik untuk masyarakat lokal maupun bagi wisatawan. Pengembangan ekowisata di kawasan pesisit Desa Sarawet membuka peluang bagi masyarakat untuk mengembangkan kesejahteraan, bahkan dapat menikmati hasil dari industri wişata yang dikembangkan, terutama pengembangan ekowisata akan memberikan dampak positif bagi kawasan pesisir Desa Serawet.

\section{Hasil Penilaian (Scoring) Potensi Ekowisata di Kawasan Pesisir Desa Sarawet}

- Berdasarkan informasi penting yang didapat padalokasi penelitian, maka dilakukan pembobotan pada sembilan belas (19) kategori penilaian potensi ekowisata yang dapat dilihat pada Tabel 4. Di kawasan pesisir Sarawet memiliki potensi sumberdaya alam yang tinggi, walaupun tingkat pendidikan masyarakat masih rendah, dan penataan kawasan masih harus dikembangkan lagi. Dari hasil pembobotan tingkat kelayakan berada pada level yang moderat, kawasan ini bisa dan layak dikembangkan menjadi suatu kawasan ekowisata. Priskin
(2001) menyatakan suatu kawasan dapat dikembangkan sebagai objek wisata alam bila memiliki komponen-komponen potensi, minimal pada level moderat.

\section{KESIMPULAN}

Kawasan pesisir Desa Sarawet memiliki potensi ekowisata yang meliputi potensi sumberdaya alam yang sangat tinggi. Potensi yang dimiliki kawasan pesisir Desa Sarawet sebagai kawasan ekowisata dianggap layak untuk dikernbangkan. Berdasarkan evaluasi Metode Priskin melalui variabel sumberdaya alam, sosial-ekollom, budaya lokal, institusional, infrastrukturf kawasan, dan kemungkinan dampak, maka kawasan pesisir Desa Sarawet layak untuk dikembangkan sebagai kawasan ekowisata.

\section{UCAPAN'TERIMA KASIH}

Tulisan ini merupakan bagian dari Tesis Program Magister Sains dari Penulis Pertama. Terima kasih kepada Dr. Ir. Adnan Wantasen, M.Si dane Ir. Stephanus V. Mandagi, M.Sc, Ph.D. yang telah banyak membantu Penulis dalam menyelesaikan studi pada Program Pascasarjana Universitas Sam Ratulangi Manado juga kepada aparat Desa Sarawet atas kerjasamanya selama penelitian.

\section{DAFTAR PUSTAKA}

[BPHM] Balai Pengelola Hutan Mangrove, 2000. Visi dan Misi BPHM-I.

Damanik, J. dan H. F. Weber, 2006. Perencanaan Ekowisata. Dari Teori ke Aplikasi. Pusat Studi Pariwisata UGM \& Penerbit Andi, Yokyakarta.

Fachrul. M.F. 2007. Metode Sampling Bioekologi.PT Bumi Aksara. Jakarta.

Ludwig. J.A. and J.F. Reynolds. 1988. Statistical Ecology. A Primer on Methods and Computing. A. Wiley Interscience Publication John and Son, Inc. Canada. pp 337.

Mueller-Dumbois dan Ellenberg.1974. Aims and Methode of Vegetation Ecology. John Wiley and sons, Inc. USA.

Odum, P.E. 1971. Dasar-dasar Ekologi.Terjemahan Thahjono Samingan. Cet 2. Gadjah Mada University Press. Yogyakarta

Priskin, J. 2001. Assessment of Natural Resources for Nature-based Tourism: The Case of The Central Coast Region of Western Australia. Tourism Management Journal, 22 (2001) 634-648 pp.

Soegianto, A. 1994. Ekologi Kuantitatif. Penerbit Usaha Nasional. Surabaya. 173 hal.

Widigdo, B. 2000. Diperlukan Pembakuan Kriteria EkoBiologis Untuk Menentukan "Potensi Alami" Kawa- 
san Pesisir Untuk Budidaya Udang. Dalam : Prosiding Pelatihan Untuk Pelatih Pengelolaan Wilayah Pesisir Terpadu. Pusat Kajian Sumberdaya Pesisir dan Lautan
-Institut Pertanian Bogor dan Proyek Pesisir dan Coastal Resources Center-University of Rhode Island. Bogor, Indonesia.

Tabel 4. Hasil Pembobotan dari 19 Kategori Penilaian Potensi Ekowisata

\begin{tabular}{|c|c|c|c|c|}
\hline \multirow{3}{*}{ Variabel Penelitian } & \multirow{3}{*}{ Kategori } & \multicolumn{3}{|c|}{ Pembobotan (S) } \\
\hline & & Rendah & Moderat & Tinggi \\
\hline & & $1-2$ & 3 & $4-5$ \\
\hline \multirow[t]{2}{*}{ (1)Sumberdaya Alam } & 1. Perairan Pesisir & & & \\
\hline & 1)Terdapat ekosistem atraktif & & & 5 \\
\hline \multirow[t]{3}{*}{ (2)Budaya Lokal } & 2)Ada atraksi budaya (atraktif) & & 3 & \\
\hline & 3)Ada kearifan Lokal & & 3 & \\
\hline & 4)Ada produk kerajinan & & 3 & \\
\hline \multicolumn{2}{|c|}{ Tingkat Pembobotan (1) dan $(2)\left(\sum \mathrm{S} / 4\right)$} & & & 10,2 \\
\hline \multirow[t]{3}{*}{ (3) Sosial-Ekonomi Masyarakat Lokal } & 5)Tingkat pendidikan & 2 & & \\
\hline & 6) Jenis pekerjaan & & & 5 \\
\hline & 7)Kebiasaan hidup masyarakat & & & 5 \\
\hline \multirow[t]{8}{*}{ (4)Infrastruktur Kawasan } & 1. Fisik & & & \\
\hline & 8)Aksesibilitas & & & 5 \\
\hline & 9)Fasilitas & & 3 & \\
\hline & 10)Penataan Kawasan & & & \\
\hline & 11)Keberadaan objek wisata & & 3 & \\
\hline & 2. Non Fisik & & & \\
\hline & 12)Keamanan \& kenyamanan & & & 5 \\
\hline & 13)Persepsi tentang Ekowisata & & & 5 \\
\hline \multirow[t]{5}{*}{ (5) Institusional } & 1. Kelembagaan & & & \\
\hline & 14)Tingkat lokal & & 3 & \\
\hline & 2. Regulasi & & & \\
\hline & 15)Tingkat lokal & & & 4 \\
\hline & 16)Nasional & & & 4 \\
\hline \multirow[t]{4}{*}{ (6)Kemungkinan Dampak } & 1. Terhadap sumberdaya alam & & & \\
\hline & 17)Terhadap ekosistem & & & 5 \\
\hline & 18)Terhadap biøta & & & 5 \\
\hline & 2. 19)Terhadap masyarakat & & & 5 \\
\hline \multicolumn{2}{|c|}{ Tingkat Pembobotan (3), (4), (5), dan (6) $\left(\sum S / 15\right)$} & & & 61 \\
\hline \multicolumn{2}{|c|}{ Tingkat Pembobotan untuk semua Variabel $\left(\sum \mathrm{S} / 19\right)$} & & & 3,7 \\
\hline
\end{tabular}

